\title{
A theoretical analysis of the conformational behaviour of substituted methylenecyclohexanes
}

\author{
Robert C. Mawhinney, Heidi M. Muchall, and J ean Lessard
}

\begin{abstract}
The use of the PBE0 hybrid density functional theory method in conjunction with the COSMO solvation model allowed us to reproduce, both qualitatively and quantitatively, the experimentally observed conformational compositions of 2-substituted and 2,7-disubstituted methylenecyclohexanes. An analysis revealed several different interactions that influence the overall equilibrium. It was found that the endo (general) anomeric effect plays a significant role in the equilibrium and that the "unsaturation effect" possibly comprises two effects.
\end{abstract}

Key words: conformational analysis, methylenecyclohexanes, anomeric effect, unsaturation effect.

Résumé : L'utilisation de la méthode théorique fonctionnelle de densité hybride PBE0 de concert avec le modèle de solvatation COSMO nous permet de reproduire qualitativement et quantitativement, les compositions conformationnelles, observées expérimentalement, des méthylènecyclohexanes substitués en position 2 et disubstitués en positions 2 et 7. Une analyse révèle plusieurs interactions différentes qui influencent l'équilibre global. On a trouvé que l'effet anomère endo (général) joue un rôle important dans l'équilibre et que l'effet d'insaturation comporte probablement deux effets.

Mots clés : analyse conformationnelle, méthylènecyclohexanes, effet anomère, effet d'insaturation.

[Traduit par la Rédaction]

\section{Introduction}

The anomeric effect is invoked to explain the unusual stability of the more sterically unfavoured synclinal (gauche) conformer over the sterically favoured antiperiplanar (anti) conformer (1). A number of theories have been hypothesized to explain these findings (2). To test these theories, Lessard and co-workers (3-6) assessed the equilibrium composition of a number of systems using ${ }^{13} \mathrm{C}$ NMR spectroscopy, including substituted methylenecyclohexanes.

The first article in the series (3) revealed that the dipoledipole - dipole-quadrupole and rabbit-ear (or $n-n$ interaction) theories for the anomeric effect were negligible (the latter because the chosen system did not have any endocyclic atoms with electron lone pairs), leaving only the double bond - no bond resonance or $\pi_{\mathrm{C}=\mathrm{C}}-\sigma_{\mathrm{C}-\mathrm{O}}^{*}$ orbital overlap as the main interaction. This appeared to explain the finding that the introduction of a methoxy substituent to the methylene group (position 7) in 2-methoxymethylenecyclohexane led to a stabilization of the axial conformer to such an extent that the equatorial conformer was not observed.

In the second paper (4) this was explored further by changing the 2-substituent. It was found that the introduction of a $\pi$ system had the unexpected result of switching the

Received 23 June 2003. Published on the NRC Research Press Web site at http://canjchem.nrc.ca on 2 October 2003.

R.C. Mawhinney and H.M. Muchall. ${ }^{1}$ Department of Chemistry and Biochemistry, Concordia University, Montreal, QC H4B 1R6, Canada.

J. Lessard. Département de Chimie, Université de

Sherbrooke, Sherbrooke, QC J1K 2R1, Canada.

${ }^{1}$ Corresponding author (e-mail: muchall@alcor.concordia.ca). conformer preference from axial to equatorial, with the proportion of equatorial orientation on going from methoxy (OMe) to vinyloxy (OVi) to acetoxy (OAc) increasing from $41 \%$ to $61 \%$ to $80 \%$ at $0{ }^{\circ} \mathrm{C}$. Based on double bond - no bond resonance, the increase in anion stability of the 2 -substituent along this series should produce the opposite effect. Similarly, the $\pi_{\mathrm{C}=\mathrm{C}}-\sigma_{\mathrm{C}-\mathrm{O}}^{*}$ interaction should become more pronounced, since the $\sigma_{\mathrm{C}-\mathrm{O}}^{*}$ orbital energy should decrease along the series. This counter observation was termed the "unsaturation effect".

Instead of invoking a double bond - no bond resonance or $\pi_{\mathrm{C}=\mathrm{C}}-\sigma_{\mathrm{C}-\mathrm{O}}^{*}$ stabilizing interaction, a number of these results could also have been explained through an $n_{\mathrm{O}}-\pi_{\mathrm{C}=\mathrm{C}}^{*}$ stabilizing interaction. To examine the effect of the $n_{\mathrm{O}}-\pi_{\mathrm{C}=\mathrm{C}}^{*}$ interaction, Lessard et al. (5) examined a series of 7-substituted 2-methoxymethylenecyclohexanes. The substituent on the methylene carbon was changed from hydrogen to methoxy $(\mathrm{OMe})$, phenyl $(\mathrm{Ph})$, and cyano $(\mathrm{CN})$, and the observed proportion of equatorial orientation changed from $41 \%\left(0{ }^{\circ} \mathrm{C}\right)$ to $<5 \%\left(-113{ }^{\circ} \mathrm{C}\right), 12 \%\left(-113{ }^{\circ} \mathrm{C}\right)$, and $88 \%\left(-60{ }^{\circ} \mathrm{C}\right)$, respectively. These results showed that $n_{\mathrm{O}}-\pi_{\mathrm{C}=\mathrm{C}}^{*}$ orbital interactions are not the dominant factor for determining the equilibrium composition.

In the last paper of this series (6), the authors brought together all previous results, as well as those for several similar systems, and concluded that the generalized anomeric effect is operating in these systems along with a contribution from electrostatic (dipole-quadrupole) interactions. Most important, however, is the as yet unexplained "unsaturation effect", which appears to override the generalized anomeric effect in a number of cases.

To understand the "unsaturation effect", we started a computational study of the axial preference for the 2-substituted 
methylenecyclohexanes (7). The experimentally observed trend was reproduced qualitatively. While the equilibria for the methoxy- and vinyloxy-substituted compounds were best obtained at single point solvated levels of theory, the large equatorial preference for the acetoxy species could only be reproduced when solvent-optimized geometries and energies were employed. Even then the equilibrium composition could only be estimated, since a minimum for one of the conformers was not located.

In this paper we have undertaken a reexamination of the 2 -substituted equilibrium compositions. We report that the use of the COSMO solvation model (8-10) in conjunction with the empirical-parameter-free PBE0 hybrid density functional method $(11,12)$ not only correctly predicts the compositional preferences in the 2-substituted methylenecyclohexanes but also those seen for the 2,7-disubstituted systems (Scheme 1). This combination of theory and solvation model has recently been shown to give reliable results for examining the role of stereoelectronic effects in the collagen dipeptide (13).

\section{Computational details}

The Gaussian 98 suite of programs was used in all calculations (14). The minimum energy conformations were optimized using the empirical-parameter-free hybrid density functional PBE0 $(11,12)$ and the Pople split valence 6$31 \mathrm{G}(\mathrm{d})$ basis set (15-19), starting from the previously optimized gas phase HF/6-31G(d) structures (7). The COSMO polarizable continuum solvent model (8-10) was used, with dichloromethane as solvent, in all optimizations. All minima were confirmed by harmonic vibrational frequency analyses. Since all relative energies are based on rotational conformers, there is negligible dependence on entropy, and we report zero-point corrected, as opposed to free energy, values.

\section{Results and discussion}

As in the previous work (7), rotational isomers for both the axial and equatorial conformers were explored. In all cases, two rotamers are obtained within a $2.5 \mathrm{kcal} / \mathrm{mol}$ cutoff criterion. In Fig. 1 the structures for 2-OMe are given. As one can see, the $\mathrm{O}-\mathrm{R}^{1}$ bond is aligned antiperiplanar with one of two possible $\mathrm{C}-\mathrm{C}$ bonds, either $\mathrm{C}-\mathrm{C}_{s p^{3}}$ or $\mathrm{C}-\mathrm{C}_{s p^{2}}$. This general feature is the same in all systems. All species will from here on be labelled by their conformations, axial (a) or equatorial (e), antiperiplanar to $\mathrm{C}_{s p^{3}}$ or $\mathrm{C}_{s p^{2}}$ (i.e., $\left.\mathrm{a}\left(s p^{3}\right), \mathrm{a}\left(s p^{2}\right), \mathrm{e}\left(s p^{3}\right), \mathrm{e}\left(s p^{2}\right)\right)$, as shown in Fig. 1. In the case of the vinyloxy-substituted system there are twice as many conformers because of the cis and trans orientations in the $\mathrm{C}-\mathrm{O}-\mathrm{CH}=\mathrm{CH}_{2}$ fragment. While also possible for the acetoxy substituent, it was found earlier (7) that the cis species lie around $8 \mathrm{kcal} / \mathrm{mol}$ higher in energy and therefore are not a factor in the equilibrium composition. Unlike the previous study, we have now been able to locate solvent-optimized minima for all four conformers in the acetoxy system and can therefore concentrate on understanding the causes of the effects that lead to the observed equilibria.

\section{Compositional analysis}

The experimentally observed axial:equatorial equilibrium composition for the 2-substituted methylenecyclohexanes is
Scheme 1.
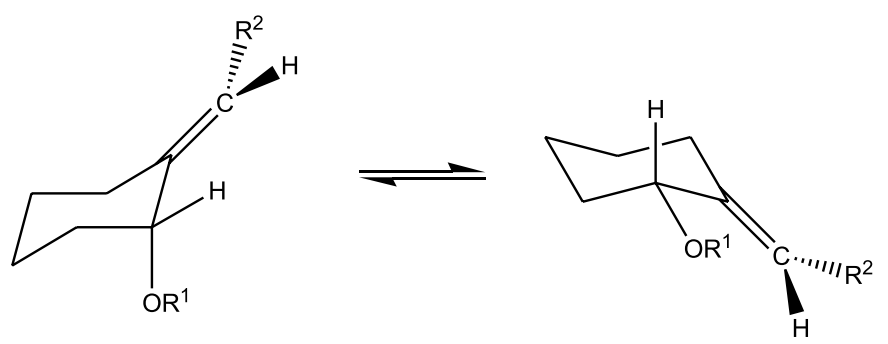

$$
\begin{aligned}
& \text { 2-substituted } \\
& \mathrm{R}^{2}=\mathrm{H} ; \mathrm{R}^{1}=\mathrm{CH}_{3} \text { (2-OMe) } \\
& \mathrm{R}^{2}=\mathrm{H} ; \mathrm{R}^{1}=\mathrm{CH}=\mathrm{CH}_{2} \text { (2-OVi } \text { cis and trans) } \\
& \mathrm{R}^{2}=\mathrm{H} ; \mathrm{R}^{1}=\mathrm{COCH}_{3}(\mathbf{2 - O A c}) \\
& \text { 7-substituted } \\
& \mathrm{R}^{1}=\mathrm{CH}_{3} ; \mathrm{R}^{2}=\mathrm{CN}(7-\mathrm{CN}) \\
& \mathrm{R}^{1}=\mathrm{CH}_{3} ; \mathrm{R}^{2}=\mathrm{OCH}_{3} \text { (7-OMe) } \\
& \mathrm{R}^{1}=\mathrm{CH}_{3} ; \mathrm{R}^{2}=\mathrm{C}_{6} \mathrm{H}_{5} \text { (7-Ph) }
\end{aligned}
$$

Fig. 1. Representation and labelling scheme of the two rotamers of each anomer (for 2-OMe, but all other systems exhibit the same general feature).
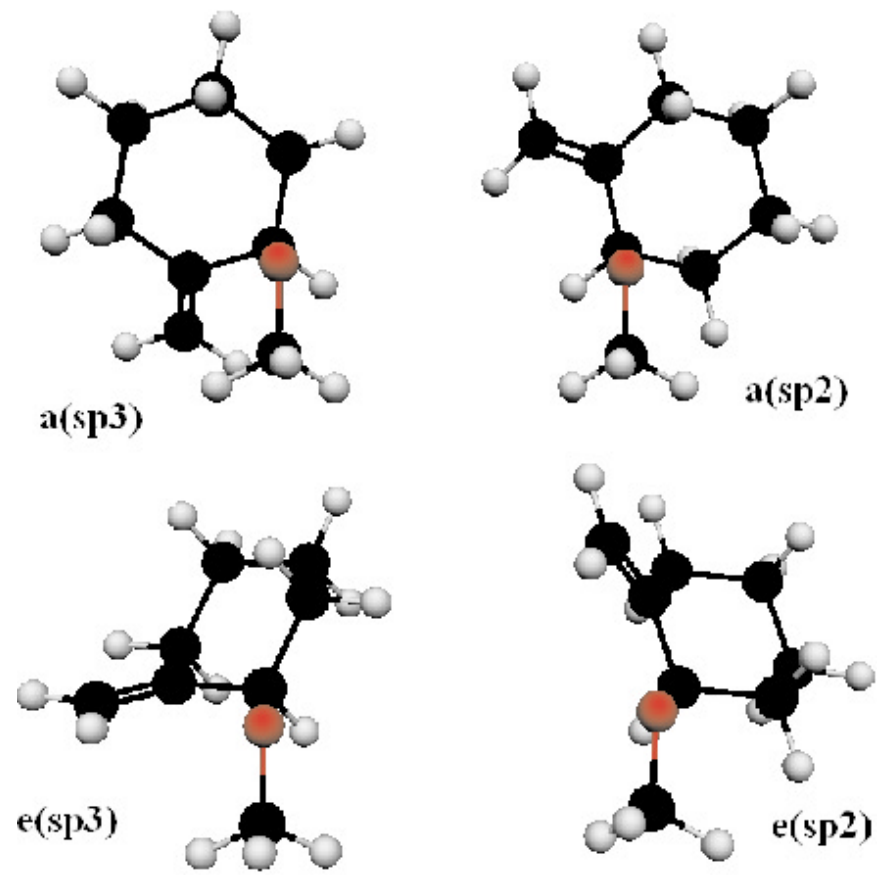

59:41 (2-OMe), 39:61 (2-OVi), and 20:80 (2-OAc) (4) and for the 7-substituted 2-methoxymethylenecyclohexane systems is $12: 88$ (7-CN), >95:<5 (7-OMe), and 88:12 (7-Ph) (5). The relative energy differences for each of the species that make up the equilibrium are given in Table 1 . The equilibium composition is derived from these energy differences by combining the Boltzmann distribution relationship with the molar fractions distribution relationship $(20,21)$. As shown in Table 1, our results are both qualitatively and quantitatively in good agreement with the experimental values. The largest differences are observed for 2-OVi $(\Delta=$ $-12 \%)$ and 7-Ph $(\Delta=+16 \%)$. All other results are within at 
Table 1. Relative energies ${ }^{a}$ and equilibrium compositions (evaluated at experimental temperatures).

\begin{tabular}{|c|c|c|c|c|c|c|c|}
\hline & 2-OMe ${ }^{b}$ & $\begin{array}{l}\mathbf{2 - O V i} \\
(\text { trans })^{b}\end{array}$ & 2-OVi $(c i s)^{b}$ & 2-OAc $c^{b}$ & $7-\mathrm{CN}^{c}$ & 7-OMe ${ }^{c}$ & 7-Ph ${ }^{d}$ \\
\hline \multicolumn{8}{|c|}{$\Delta \mathrm{E}(\mathrm{kcal} / \mathrm{mol})$} \\
\hline $\mathrm{a}\left(s p^{3}\right)$ & $0.00^{e}$ & 0.60 & 0.49 & 0.69 & 0.75 & $0.00^{e}$ & $0.00^{e}$ \\
\hline $\mathrm{a}\left(s p^{2}\right)$ & 2.03 & 1.03 & 1.63 & 0.95 & 2.20 & 1.71 & 1.55 \\
\hline $\mathrm{e}\left(s p^{3}\right)$ & 0.35 & $0.00^{e}$ & 0.12 & 0.13 & $0.00^{e}$ & 1.69 & 0.57 \\
\hline $\mathrm{e}\left(s p^{2}\right)$ & 0.91 & 0.53 & 0.65 & $0.00^{e}$ & 0.03 & 1.51 & 0.85 \\
\hline $\mathrm{a}\left(s p^{2}\right)$ & 1.4 & $\begin{array}{c}4.4 \\
(8.1)^{f}\end{array}$ & $\begin{array}{c}1.5 \\
(3.2)^{f}\end{array}$ & 7.7 & 0.1 & 0.5 & 1.8 \\
\hline $\mathrm{e}\left(s p^{3}\right)$ & 30.3 & $\begin{array}{c}29.3 \\
(53.9)^{f}\end{array}$ & $\begin{array}{c}23.5 \\
(51.5)^{f}\end{array}$ & 35.3 & 49.9 & 0.5 & 18.4 \\
\hline exptl. & 59 & & 39 & 20 & 12 & $>95$ & 88 \\
\hline
\end{tabular}

${ }^{a}$ Relative energies include zero-point vibrational corrections.

${ }^{b}$ Equilibrium composition evaluated at $0{ }^{\circ} \mathrm{C}$.

${ }^{c}$ Equilibrium composition evaluated at $-113{ }^{\circ} \mathrm{C}$.

${ }^{d}$ Equilibrium composition evaluated at $-60{ }^{\circ} \mathrm{C}$.

${ }^{e}$ Total energies (in hartree $\left(1\right.$ hartree $\left.=4.3597482 \times 10^{-18} \mathrm{~J}\right)$ for the lowest energy conformers: $-387.813339(\mathbf{2 - O M e}),-425.849143(\mathbf{2 - O V i})$, -501.049114 (2-OAc), -479.96288 (7-CN), -502.179296 (7-OMe), -618.517203 (7-Ph).

${ }^{f}$ cis and trans components separated.

least 7\%, and for three systems (2-OMe, 2-OAc, and 7OMe) there is no appreciable error.

In the 2-substituted systems, the major change in equilibrium composition on going from methoxy (2-OMe) to vinyloxy (2-OVi) is a decrease in a $\left(s p^{3}\right)$ (from 57.5 to $21.6 \%$ $(9.7($ trans $)+11.9($ cis $)))$ and a concomitant increase in $\mathrm{e}\left(s p^{3}\right)$ (from 30.3 to $52.8 \%$ ). In 2-OAc, the decrease in a $\left(s p^{3}\right)$ is accompanied by an additional major increase in $\mathrm{e}\left(s p^{2}\right)$ (from 10.8 to $44.5 \%$ ). In the 7 -substituted series, the introduction of the cyano group (7-CN) has a similar effect to that of the acetoxy group (2-OAc) in the 2-substituted series. The exchange of the hydrogen atom in 2-OMe for a phenyl ring (7$\mathbf{P h})$ in the 7-position has only a small effect on the energy differences, stabilizing $\mathrm{a}\left(s p^{2}\right)$ and destabilizing $\mathrm{e}\left(s p^{3}\right)$, thereby shifting the equilibrium composition further towards axial. The 7-methoxy substitution (7-OMe) dramatically destabilizes both equatorial species so that a $\left(s p^{3}\right)$ now makes up $\sim 98 \%$ of the equilibrium.

\section{Geometric evidence}

The anomeric effect, aside from energetic considerations, is typically accompanied by certain geometric changes that form the basic reasoning behind a number of its explanations (1). In particular, the $\mathrm{C}-\mathrm{X}$ bond in the anomeric position is usually observed to be elongated in the axial conformer with respect to the equatorial conformer. This is also the case here, as shown for the $\mathrm{C}-\mathrm{O}$ bond distances given in Table 2. In all 2-methoxy systems (2-OMe, 7-CN, 7-OMe, and 7-Ph) the difference between the axial and equatorial $\mathrm{C}-\mathrm{O}$ distance is ca. $0.012 \AA$. This difference increases as the electronegativity of the 2-substituent increases, as expected for an anomeric effect. This is demonstrated by a difference of $0.015 \AA$ in $\mathbf{2 - O V i}$ and a difference of $0.018 \AA$ in 2-OAc. These results are consistent with the conclusions of Lessard and co-workers that the generalized anomeric effect is operating in these systems (6).

The $\mathrm{C}-\mathrm{O}$ bond distances in both axial and equatorial conformers increase as the electronegativity of the 2substituent increases. This in itself is not surprising. What is surprising is that the $\mathrm{C}-\mathrm{O}$ bond distance is affected by 7 substitution. For example, the addition of the electronwithdrawing cyano group (7-CN) shortens $r_{\mathrm{C}-\mathrm{O}}$ with respect to the unsubstituted system (2-OMe). The addition of an electron-donating group (7-OMe) is accompanied by an increase in $r_{\mathrm{C}-\mathrm{O}}$, and conjugation (7-Ph) elicits no change. An examination of the $r_{\mathrm{C}-\mathrm{O}}$ differences between axial and equatorial species also shows this trend. The difference of $0.012 \AA$ (as assessed using the raw bond distances from which Table 2 was created) in the unsubstituted 2-OMe decreases to $0.011 \AA$ with the addition of an electronwithdrawing group (7-CN), increases to $0.013 \AA$ with an electron-donating group (7-OMe), and is unchanged $(0.012 \AA)$ by conjugation (7-Ph). This remote effect implies that the methylene $\pi$ system has an effect on both anomers and is probably part of the reason behind the "unsaturation effect".

The operation of another effect, the exo-anomeric effect, is revealed by the $r_{\mathrm{C}-\mathrm{C}}$ entries in Table 2 . When $\mathrm{O}-\mathrm{R}^{1}$ is antiperiplanar to $\mathrm{C}_{s p^{3}}$ (left hand structures in Fig. 1), the overlap between an oxygen lone pair $\left(n_{\mathrm{O}}\right)$ and $\sigma_{\mathrm{C}-\mathrm{C}_{s p} 2}^{*}$ is maximized. Consequently, $r_{\mathrm{C}_{-} \mathrm{C}_{s p}{ }^{2}}$ is found to be longer in $\mathrm{a}\left(s p^{3}\right)$ and $\mathrm{e}\left(s p^{3}\right)$ than in $\mathrm{a}\left(s p^{2}\right)$ and $\mathrm{e}\left(s p^{2}\right)$ (Table 2). Simi- 
Table 2. Selected bond lengths ( $)$.

\begin{tabular}{|c|c|c|c|c|c|c|c|}
\hline & 2-OMe & 2-OVi $($ trans $)$ & 2-OVi (cis) & 2-OAc & $7-\mathrm{CN}$ & 7-OMe & 7-Ph \\
\hline \multicolumn{7}{|l|}{$r_{\mathrm{C}-\mathrm{O}}$} & 1.421 \\
\hline $\mathrm{a}\left(s p^{2}\right)$ & 1.423 & 1.435 & 1.436 & 1.452 & 1.419 & 1.427 & 1.422 \\
\hline $\mathrm{e}\left(s p^{3}\right)$ & 1.409 & 1.420 & 1.420 & 1.433 & 1.406 & 1.413 & 1.409 \\
\hline $\mathrm{e}\left(s p^{2}\right)$ & 1.411 & 1.420 & 1.421 & 1.434 & 1.406 & 1.414 & 1.410 \\
\hline \multicolumn{8}{|l|}{$r_{\mathrm{C}-\mathrm{C}_{s p^{2}}}$} \\
\hline $\mathrm{a}\left(s p^{3}\right)$ & 1.512 & 1.510 & 1.509 & 1.507 & 1.512 & 1.505 & 1.514 \\
\hline $\mathrm{a}\left(s p^{2}\right)$ & 1.508 & 1.507 & 1.506 & 1.505 & 1.507 & 1.502 & 1.510 \\
\hline $\mathrm{e}\left(s p^{3}\right)$ & 1.512 & 1.510 & 1.509 & 1.506 & 1.509 & 1.510 & 1.515 \\
\hline $\mathrm{e}\left(s p^{2}\right)$ & 1.508 & 1.507 & 1.505 & 1.504 & 1.504 & 1.506 & 1.510 \\
\hline \multicolumn{8}{|l|}{$r_{\mathrm{C}-\mathrm{C}_{s p}{ }^{3}}$} \\
\hline $\mathrm{a}\left(s p^{3}\right)$ & 1.526 & 1.526 & 1.524 & 1.522 & 1.527 & 1.526 & 1.528 \\
\hline $\mathrm{a}\left(s p^{2}\right)$ & 1.533 & 1.531 & 1.529 & 1.527 & 1.534 & 1.533 & 1.534 \\
\hline $\mathrm{e}\left(s p^{3}\right)$ & 1.528 & 1.528 & 1.526 & 1.526 & 1.531 & 1.527 & 1.530 \\
\hline $\mathrm{e}\left(s p^{2}\right)$ & 1.534 & 1.531 & 1.530 & 1.528 & 1.536 & 1.533 & 1.536 \\
\hline \multicolumn{8}{|l|}{$r_{\mathrm{C}=\mathrm{C}}$} \\
\hline $\mathrm{a}\left(s p^{3}\right)$ & 1.333 & 1.332 & 1.333 & 1.332 & 1.345 & 1.337 & 1.343 \\
\hline $\mathrm{a}\left(s p^{2}\right)$ & 1.332 & 1.332 & 1.332 & 1.332 & 1.344 & 1.336 & 1.343 \\
\hline $\mathrm{e}\left(s p^{3}\right)$ & 1.332 & 1.331 & 1.332 & 1.331 & 1.344 & 1.335 & 1.342 \\
\hline $\mathrm{e}\left(s p^{2}\right)$ & 1.332 & 1.332 & 1.332 & 1.332 & 1.344 & 1.335 & 1.342 \\
\hline
\end{tabular}

larly, when $\mathrm{O}-\mathrm{R}^{1}$ is antiperiplanar to $\mathrm{C}_{s p^{2}}$ (right hand structures in Fig. 1), the $n_{\mathrm{O}}-\sigma_{\mathrm{C}-\mathrm{C}_{s p} 3}^{*}$ interaction is maximized and $r_{\mathrm{C}-\mathrm{C}_{s p} 3}$ is longer in these species. These results also demonstrate that the effect on distance is larger in $\mathrm{C}-\mathrm{C}_{s p^{3}}$ than in $\mathrm{C}-\mathrm{C}_{s p^{2}}$. For example, in the 2-OMe case the former changes by $0.006-0.007 \AA$ and the latter by $0.004 \AA$. This is a reflection of the differing strengths of the $\mathrm{C}_{s p^{3}}-\mathrm{C}_{s p^{3}}$ and $\mathrm{C}_{s p^{3}}-\mathrm{C}_{s p^{2}}$ bonds, as shown by the shorter overall $\mathrm{C}_{s p^{3}}-\mathrm{C}_{s p^{2}}$ distances.

As expected, this effect diminishes as $\mathrm{O}-\mathrm{R}^{1}$ becomes more electronegative. The average $r_{\mathrm{C}-\mathrm{C}_{s p}{ }^{2}}$ bond difference decreases from $0.004 \AA$ (2-OMe) to $0.003 \AA \mathbf{( 2 - O V i )}$ and to $0.002 \AA$ (2-OAc). Similarly, the average $r_{\mathrm{C}-\mathrm{C}_{s p} 3}$ bond difference decreases from $0.007 \AA$ (2-OMe) to $\sim 0.004 \AA$ (2-OVi) and $\sim 0.003 \AA$ (2-OAc). In the $r_{\mathrm{C}-\mathrm{C}_{s p 2}}$ case, there is virtually no variation in the axial and equatorial differences. The $r_{\mathrm{C}-\mathrm{C}_{s p} 3}$ case, on the other hand, exhibits some variation between the axial and equatorial differences, which also increases along the series 2-OMe, 2-OVi, and 2-OAc. The effect of 7-substitution is rather small, if present at all, and no discernable pattern can be ascertained in the $r_{\mathrm{C}_{-} \mathrm{C}_{s n^{3}}}$ case. The $r_{\mathrm{C}-\mathrm{C}_{s p^{2}}}$ bond distances reveal that the addition of an electron withdrawing group increases the $s p^{3}-s p^{2}$ difference in both anomers (7-CN), an electron-donating group decreases it in the axial anomer (7-OMe), and conjugation increases it in the equatorial anomer (7-Ph).

Aside from the changes due to 7-substitution, the $\mathrm{C}=\mathrm{C}$ distance is fairly insensitive, owing to the stiffness of the bond (even more so than for the $\mathrm{C}_{s p^{3}}-\mathrm{C}_{s p^{2}}$ bond). This is expected, and the lack of any appreciable change in $\mathrm{C}=\mathrm{C}$ distance on its own does not imply that $\pi_{\mathrm{C}=\mathrm{C}}-\sigma_{\mathrm{C}-\mathrm{O}}^{*}$ and $n_{\mathrm{O}}-\pi_{\mathrm{C}=\mathrm{C}}^{*}$ interactions do not play a significant role in these systems, as has been concluded earlier $(3,5)$. In fact, the ex- pected small lengthening of the $\mathrm{C}=\mathrm{C}$ bond in the axial species can be seen most clearly in 7-OMe and 7-Ph.

\section{Decomposition of energy differences}

The equilibrium composition depends on the energy differences between the different species, as described earlier. As well, the Edward-Lemieux effect (which incorporates both the endo- and exo-anomeric effects, similar to our case) can be "energetically quantified by the energy difference between the sum of the endo- and exo-anomeric effects for one of the anomers and the sum for the other anomer" (22). Within this context, we have plotted the energy relationships between the different conformers (the cis and trans components of vinyloxy have been separated) as a function of the $\%$ axial composition (all calculated at $0{ }^{\circ} \mathrm{C}$ ). The overall results, along with the linear trend lines and corresponding correlation coefficients, are presented in Fig. 2.

In most cases there does not seem to be any direct relationship between energy difference and equilibrium composition. The one exception is the $\mathrm{e}\left(s p^{3}\right)-\mathrm{a}\left(s p^{3}\right)$ energy difference, where there is a strong correlation $\left(r^{2}=0.97\right)$. This relationship corresponds to the endo- (generalized) anomeric effect, as Lessard and co-workers have concluded (6). However, our results do not show a second overall effect offsetting it; perhaps there are two effects within the subsets that are masking each other on a global scale. To explore this further, we have separated out the two systems, 2-OMe, 2-OVi(cis), 2-OVi(trans), and 2-OAc ("2-substituted") and 2-OMe, 7-CN, 7-OMe, and 7-Ph ("7-substituted") and again plotted the energy differences between the different conformers as a function of the $\%$ axial composition. These are given in Figs. 3 and 4, respectively. 
Fig. 2. The overall relationship between energy differences (kcal/mol) and \% axial composition: $\boldsymbol{\Delta} E_{\mathrm{a}\left(s p^{2}\right)}-E_{\mathrm{a}\left(s p^{3}\right)} ; \boldsymbol{B}_{\mathrm{e}\left(s p^{2}\right)}-E_{\mathrm{e}\left(s p^{3}\right)} ; \times$ $E_{\mathrm{e}\left(s p^{3}\right)}-E_{\mathrm{a}\left(s p^{3}\right)} ; \boldsymbol{\square} E_{\mathrm{e}\left(s p^{2}\right)}-E_{\mathrm{a}\left(s p^{2}\right)}$.

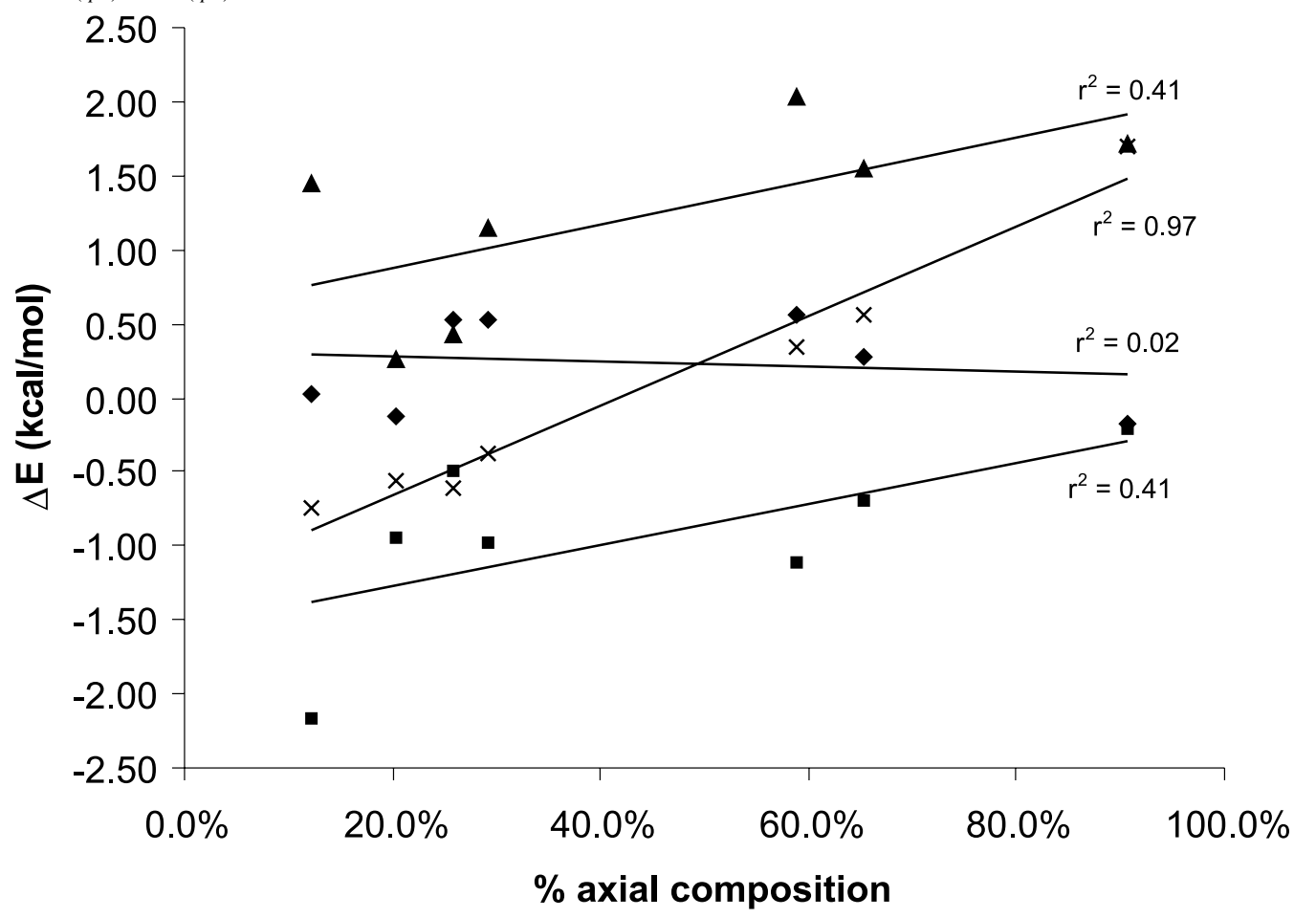

Fig. 3. The relationship between energy differences $(\mathrm{kcal} / \mathrm{mol})$ and $\%$ axial composition in the 2-substituted systems: $\boldsymbol{\Delta} E_{\mathrm{a}\left(s p^{2}\right)}-$ $E_{\mathrm{a}\left(s p^{3}\right)} ; E_{\mathrm{e}\left(s p^{2}\right)}-E_{\mathrm{e}\left(s p^{3}\right)} ; \times E_{\mathrm{e}\left(s p^{3}\right)}-E_{\mathrm{a}\left(s p^{3}\right)} ; E_{\mathrm{e}\left(s p^{2}\right)}-E_{\mathrm{a}\left(s p^{2}\right)}$.

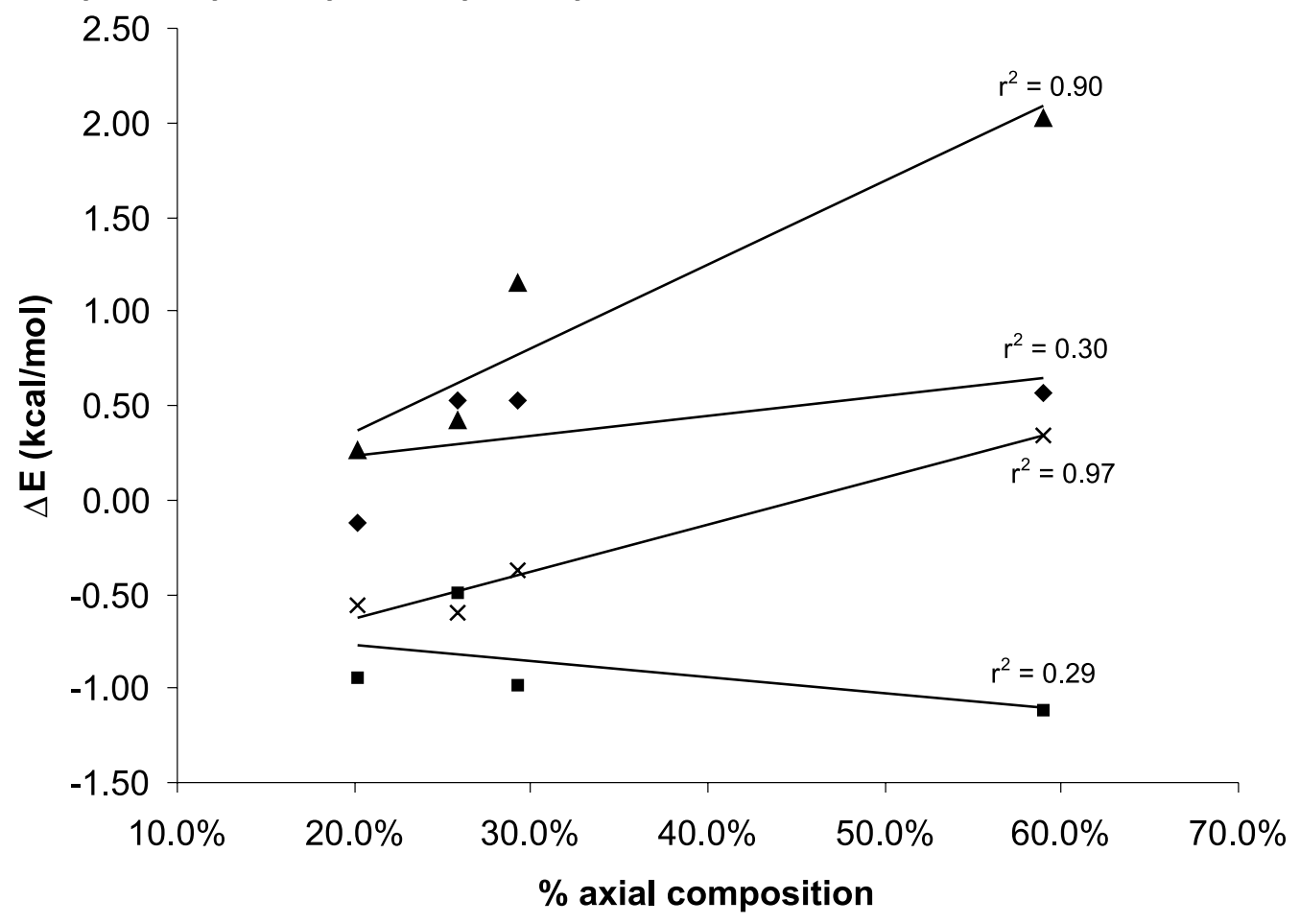

The $\mathrm{e}\left(s p^{3}\right)-\mathrm{a}\left(s p^{3}\right)$ energy difference shows the same strong correlation $\left(r^{2}=0.97\right.$ and 0.96$)$ in both 2- and 7substituted systems. In the 2-substituted systems there is also a considerable correlation $\left(r^{2}=0.90\right)$ with the exoanomeric effect in the axial conformers, a $\left(s p^{2}\right)-\mathrm{a}\left(s p^{3}\right)$, as seen in Fig. 3. The 7-substituted systems, where the 
Fig. 4. The relationship between energy differences $(\mathrm{kcal} / \mathrm{mol})$ and $\%$ axial composition in the 7-substituted systems: $\boldsymbol{\Delta} E_{\mathrm{a}\left(s p^{2}\right)}-$ $E_{\mathrm{a}\left(s p^{3}\right)} ; E_{\mathrm{e}\left(s p^{2}\right)}-E_{\mathrm{e}\left(s p^{3}\right)} ; \times E_{\mathrm{e}\left(s p^{3}\right)}-E_{\mathrm{a}\left(s p^{3}\right)} ; E_{\mathrm{e}\left(s p^{2}\right)}-E_{\mathrm{a}\left(s p^{2}\right)}$.

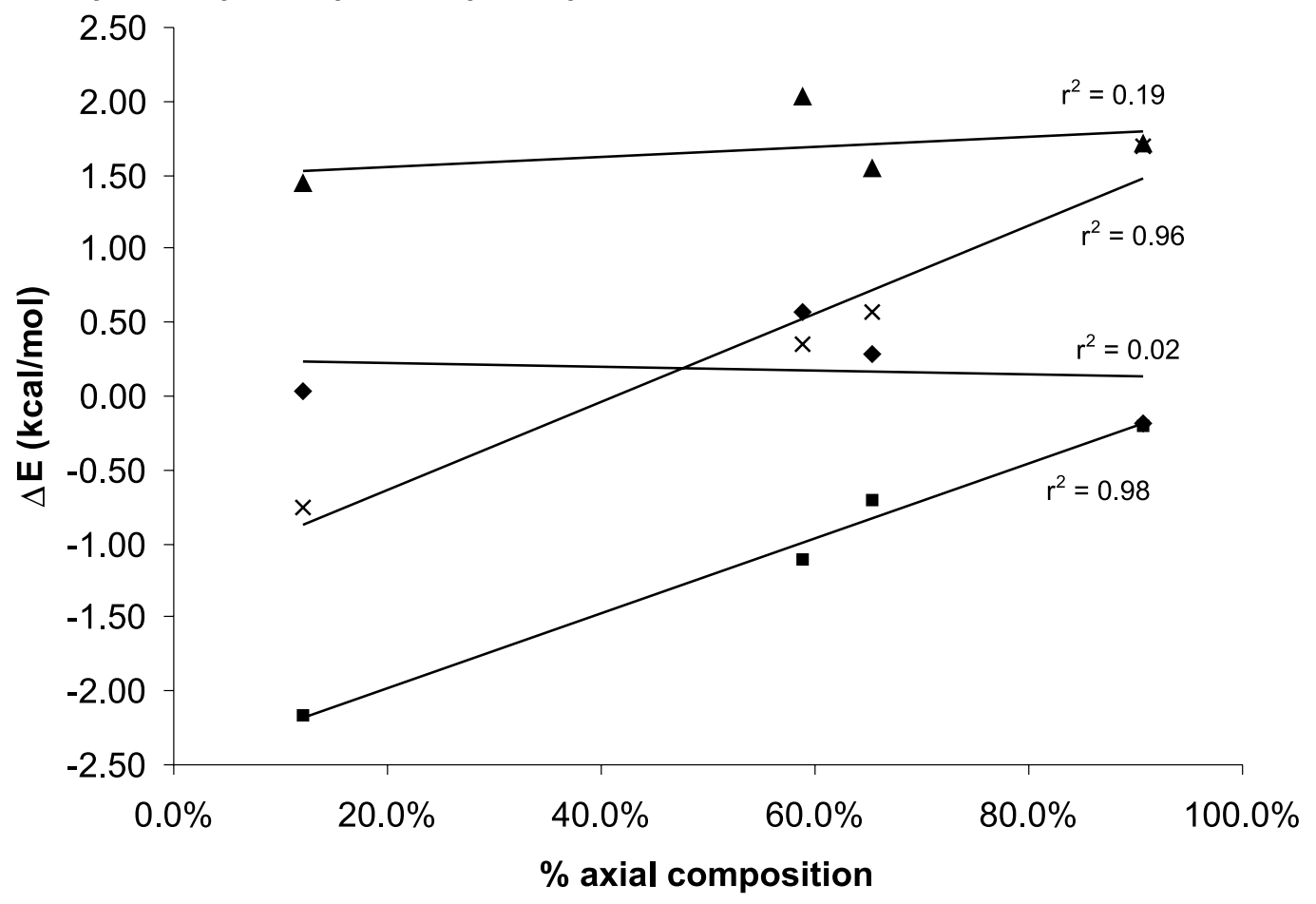

substituent effect is removed from the exo portion of the ring, do not show any correlation $\left(r^{2}=0.19\right)$ with the $\mathrm{a}\left(s p^{2}\right)-\mathrm{a}\left(s p^{3}\right)$ energy difference. They do, however, exhibit a strong correlation $\left(r^{2}=0.98\right)$ with the other endo-anomeric effect, e $\left(s p^{2}\right)-\mathrm{a}\left(s p^{2}\right)$ (Fig. 4).

The fact that there are two main trends to each series and only one of them in common suggests that the "unsaturation effect" is a combined effect. There is no straightforward explanation, and since within each conformer there are three common energy components (steric, electrostatic, and electronic) (23), a full understanding will only come from a complete analysis of all energetic contributions. Also, one must realize that most of the data points in the figures are essentially clustered at one end, as intermediate experimental data are not available at this moment. Further studies, both experimental and computational, are planned to remedy this situation.

\section{Conclusions}

In this work we have shown that the combination of PBE0 and COSMO reliably predicts the experimentally observed axial:equatorial equilibrium compositions in 2-substituted and 2,7-disubstituted methylenecyclohexanes. We have analyzed the compositions with respect to both the endo- and exo-anomeric effects, jointly known as the Edward-Lemieux effect.

The geometries of the species that make up the equilibrium composition revealed evidence of three different effects. The $r_{\mathrm{C}-\mathrm{O}}$ distances exhibit the generalized anomeric effect. The exo-anomeric effect reveals itself as an increase in $\mathrm{C}-\mathrm{C}$ bond lengths due to $n_{\mathrm{O}}-\sigma_{\mathrm{C}-\mathrm{C}}^{*}$ interactions. The rigidity of the $\mathrm{C}=\mathrm{C}$ bond limits its use as a detector of
$\pi_{\mathrm{C}=\mathrm{C}}-\sigma_{\mathrm{C}-\mathrm{O}}^{*}$ and $n_{\mathrm{O}}-\pi_{\mathrm{C}=\mathrm{C}}^{*}$ interactions. However, 7substitution has an effect on $r_{\mathrm{C}-\mathrm{O}}$ in both anomers, unlike typical anomeric systems, which implies that the methylene $\pi$ system might be the source of the "unsaturation effect". This is supported by an analysis of energy differences and their relationship to the observed equilibrium composition in that an overall endo- (generalized) anomeric effect for one of the rotamers $\left(\mathrm{e}\left(s p^{3}\right)-\mathrm{a}\left(s p^{3}\right)\right)$ is accompanied by two more correlations within the subsets of 2- and 7-substituted systems.

Studies are now underway to examine this further. These include an AIM analysis (24) of the electron density, as has been done previously (25-27); an NBO analysis (28) to examine the role of the suspected orbital interactions (29-34); and a bond energy analysis (35-37), which, to our knowledge, has never been used for the examination of the anomeric effect but should reveal results about steric, electrostatic, and electronic effects similar to other energy decomposition methods (38-40). As well, experiments are underway to examine all possible permutations within the two subsets.

\section{Acknowledgments}

Calculations were performed at the Center for Research in Molecular Modeling (CERMM), which was established with the financial support of the Concordia University Faculty of Arts and Science, the Ministère de l'Éducation du Québec (MEQ), and the Canada Foundation for Innovation (CFI). This work was supported by a research grant from the Natural Sciences and Engineering Research Council of Canada (NSERC). 


\section{References}

1. A.J. Kirby. Stereoelectronic effects. Oxford University Press, New York. 1996.

2. A.J. Kirby and N.H. Williams. In Anomeric effect and associated stereoelectronic effects. Edited by G.R.J. Thatcher. ACS Symposium Series 539. American Chemical Society, Washington, D.C. 1993. pp. 55-69.

3. J. Lessard, M.T.P. Viet, R. Martino, and J.K. Saunders. Can. J. Chem. 55, 1015 (1977).

4. M.T.P. Viet, J. Lessard, and J.K. Saunders. Tetrahedron Lett. 4, 317 (1979).

5. J. Lessard, J.K. Saunders, and M.T.P. Viet. Tetrahedron Lett. 23, 2059 (1982).

6. A. Ouedraogo, T.P.V. Minh, J.K. Saunders, and J. Lessard. Can. J. Chem. 65, 1761 (1987).

7. H.M. Muchall, P.R.N. Kamya, and J. Lessard. Can. J. Chem. 81, 689 (2003).

8. V. Barone, M. Cossi, and J. Tomasi. J. Comput. Chem. 19, 404 (1998).

9. V. Barone, M. Cossi, and J. Tomasi. J. Chem. Phys. 107, 3210 (1997).

10. M. Cossi, V. Barone, R. Cammi, and J. Tomasi. Chem. Phys. Lett. 255, 327 (1996).

11. J.P. Perdew, M. Ernzerhof, and K. Burke. J. Chem. Phys. 105, 9982 (1996).

12. C. Adamo and V. Barone. J. Chem. Phys. 110, 6158 (1999).

13. R. Improta, C. Benzi, and V. Barone. J. Am. Chem. Soc. 123, 12568 (2001).

14. M.J. Frisch, G.W. Trucks, H.B. Schlegel, G.E. Scuseria, M.A. Robb, J.R. Cheeseman, V.G. Zakrzewski, J.J.A. Montgomery, R.E. Stratmann, J.C. Burant, S. Dapprich, J.M. Millam, A.D. Daniels, K.N. Kudin, M.C. Strain, O. Farkas, J. Tomasi, V. Barone, M. Cossi, R. Cammi, B. Mennucci, C. Pomelli, C. Adamo, S. Clifford, J. Ochterski, G.A. Peterson, P.Y. Ayala, Q. Cui, K. Morokuma, N. Rega, P. Salvador, J.J. Dannenberg, D.K. Malick, A.D. Rabuck, K. Raghavachari, J.B. Foresman, J. Cioslowski, J.V. Ortiz, A.G. Baboul, B.B. Stefanov, G. Liu, A. Liashenko, P. Piskorz, I. Komaromi, R. Gomperts, R.L. Martin, D.J. Fox, T. Keith, M.A. Al-Laham, C.Y. Peng, A. Nanayakkara, M. Challacombe, P.M.W. Gill, B. Johnson, W. Chen, M.W. Wong, J.L. Andres, C. Gonzalez, M. HeadGordon, E.S. Replogle, and J.A. Pople. Gaussian 98 [computer program]. Revision A.11.4. Gaussian, Inc., Pittsburgh, PA. 2002.

15. P.C. Hariharan and J.A. Pople. Theor. Chim. Acta, 28, 213 (1973).

16. P.C. Hariharan and J.A. Pople. Mol. Phys. 27, 209 (1974).

17. W.J. Hehre, R. Ditchfield, and J.A. Pople. J. Chem. Phys. 56, 2257 (1972).

18. M.S. Gordon. Chem. Phys. Lett. 76, 163 (1980).
19. R. Ditchfield, W.J. Hehre, and J.A. Pople. J. Chem. Phys. 54, 724 (1971).

20. L.G. Sillen. In Coordination chemistry. Vol. 1. Edited by A.E. Martell. Van Nostrand Reinhold, New York. 1971. pp. 481541.

21. C.F. Baes and R.E. Mesmer. The hydrolysis of cations. Wiley, New York. 1976.

22. G.R.J. Thatcher. In Anomeric effect and associated stereoelectronic effects. Edited by G.R.J. Thatcher. ACS Symposium Series 539. American Chemical Society, Washington, D.C. 1993. pp. 6-25.

23. B.M. Pinto and R.Y.N. Leung. In Anomeric effect and associated stereoelectronic effects. Edited by G.R.J. Thatcher. ACS Symposium Series 539. American Chemical Society, Washington, D.C. 1993. pp. 126-155.

24. R.F.W. Bader. Acc. Chem. Res. 18, 9 (1985).

25. N.H. Werstiuk, K.E. Laidig, and J. Ma. In Anomeric effect and associated stereoelectronic effects. Edited by G.R.J. Thatcher. ACS Symposium Series 539. American Chemical Society, Washington, D.C. 1993. pp. 176-204.

26. G. Madrid, A. Rochin, E. Juaristi, and G. Cuevas. J. Org. Chem. 66, 2925 (2001).

27. A. Vila and R.A. Mosquera. J. Phys. Chem. A, 104, 12006 (2000)

28. A.E. Reed, L.A. Curtiss, and F. Weinhold. Chem. Rev. 88, 899 (1988).

29. F. Cortes, J. Tenorio, O. Collera, and G. Cuevas. J. Org. Chem. 66, 2918 (2001).

30. L. Carballeira and I. Perez-Juste. J. Comput. Chem. 21, 462 (2000).

31. U. Salzner and P.v.R. Schleyer. J. Am. Chem. Soc. 115, 10231 (1993).

32. A.E. Reed and F. Weinhold. Israel J. Chem. 31, 277 (1991).

33. A.E. Reed and P.v.R. Schleyer. J. Am. Chem. Soc. 109, 7362 (1987).

34. A.E. Reed and P.v.R. Schleyer. Inorg. Chem. 27, 3969 (1988).

35. G.T. Velde, F.M. Bickelhaupt, E.J. Baerends, C.F. Guerra, S.J.A. Van Gisbergen, J.G. Snijders, and T. Ziegler. J. Comput. Chem. 22, 931 (2001).

36. F.M. Bickelhaupt and E.J. Baerends. In Reviews in computational chemistry. Vol. 15. Edited by K.B. Lipkowitz and D.B. Boyd. Wiley-VCH, New York. 2000. pp. 1-86.

37. G. Frenking, K. Wichmann, N. Frohlich, C. Loschen, M. Lein, J. Frunzke, and V.M. Rayon. Coord. Chem. Rev. 238-239, 55 (2003).

38. F. Grein and P. Deslongchamps. Can. J. Chem. 70, 1562 (1992).

39. F. Grein. In Anomeric effect and associated stereoelectronic effects. Edited by G.R.J. Thatcher. ACS Symposium Series 539. American Chemical Society, Washington, D.C. 1993. pp. 205-226.

40. F. Grein. J. Mol. Struct. (Theochem), 536, 87 (2001). 